\title{
Clinical Outcomes of Extrapleural Closure of a Patent Ductus Arteriosus Concomitant with Aortic Coarctation Repair
}

\author{
Ayhan Uysal, MD, ${ }^{1}$ Esra Erturk Tekin, $\mathrm{MD},{ }^{2}$ Omer Faruk Dogan, $\mathrm{MD}^{3}$ \\ ${ }^{1}$ Department of Cardiovascular Surgery, Firat University School of Medicine, Elazig, Turkey; \\ ${ }^{2}$ Department of Cardiovascular Surgery, The Health Science University, Mersin City Hospital, Mersin, Turkey; \\ ${ }^{3}$ Department of Cardiovascular Surgery, Adiyaman, University School of Medicine, Adiyaman, Turkey
}

\section{ABSTRACT}

Background: The aim of this study was to present an extrapleural approach for the closure of patent ductus arteriosus (PDA), with the repair of aortic coarctation $(\mathrm{CoA})$ in the same session, in critically ill newborns and infants as an alternative to the transpleural surgical technique.

Methods: Between December 2007 and November 2010, 44 critically ill patients with PDA and coarctation of the aorta were operated on during the same session with the extrapleural approach. The diagnoses of the patients were made by transthoracic echocardiography (TTE). We investigated the aortic arch, the length of the coarctation segment, peak-to-peak gradients, the aortic valve, and intracardiac defects prior to the surgery using TTE. Cardiac angiography was performed to determine whether the patients were suitable for an interventional approach in hemodynamically stable patients. Twenty-eight patients had congestive heart failure with mild to moderate pulmonary and systemic hypertension. The median gestational age and weight of neonates were $2.1 \mathrm{~kg}$ (range: 1.4 to $2.9 \mathrm{~kg}$ ), and 31.4 weeks (range, 28.6 to 37 weeks), respectively. During the operations, PDA was closed using double clips. Resection of coarctation with an extended end-to-end anastomosis was performed in 27 patients. Subclavian flap angioplasty was performed in four patients, and an aortic patch repair was performed in two infants. Postoperative PDA flow and residual aortic gradient were evaluated using echocardiography prior to discharge from the hospital and during the follow-up period.

Results: There were three in-hospital deaths (6.8\%). During the follow-up period, two patients died (4.8\%). The mean follow-up period was $48.3 \pm 21.5$ months (range: $29-56$ months). Patent foramen ovale, atrial septal defect, and ventricular septal defect were the additional cardiac pathologies. These were hemodynamically insignificant. We detected that the intracardiac defects closed spontaneously. During the follow-up period, recoarctation developed in six patients

Received November 12, 2020; received in revised form fanuary 18, 2021; accepted fanuary 19, 2021.

Correspondence: Omer Faruk Dogan, Department of Cardiovascular Surgery, Adryaman University School of Medicine, Altınşehir, No:1, Adiyaman, Turkey, Telephone +90 5379618660, Fax +90 (322) 4550101 (e-mail: ofdogan@ bacettepe.edu.tr).
$(20 \%)$. We found that the risk factors for recoarctation in patients were to have a gradient from coarctation area, which was higher than $\geq 50 \mathrm{mmHg}$, and the length of coarctation segment that was longer than $1 \mathrm{~cm}$ in their first operation $(P=0.033)$. The median time from the first surgery to recoarctation was $25.4 \pm 13.2$ months (range: $16-36$ months). Balloon dilatation was performed in four patients. We performed redo-surgery in the remaining two patients with recoarctation. The mean intubation time was $9.1 \pm 13.4$ hours (range: 5.8-19.8 hours). Transthoracic echocardiography showed normal left ventricular dimensions and systolic function in 34 patients during follow up (87.1\%).

Conclusion: Our experiences show that surgical repair of aortic coarctation and PDA closure at the same session may be performed safely and with acceptable mortality and morbidity via an extrapleural approach. Interventional approach as a less invasive method may be used in patients who have developed recoarctation.

\section{INTRODUCTION}

Pulmonary and systemic hypertension, and congestive heart failure may develop in children with hemodynamically significant PDA [Jaillard 2006]. In children who have a large PDA associated with aortic coarctation, the most common life-threatening problems are pulmonary hypertension and congestive heart failure [Redington 1990]. Conservative treatment may be the initial choice with fluid restriction and an intravenous administration of ibuprofen in patients without congestive heart failure (CHF) and with normal pulmonary functions. Surgery was the most common preferred option in patients with coarctation associated with PDA until the 1980s. The efficacy of transcatheter treatment and its safety during the closure of PDA and simultaneous aortic balloon dilatation in small babies or preterm infants has been reported in the early period of 1980 [Redington 1990]. Complications after surgery or transcatheter interventions, such as aortic pseudoaneurysm, hemorrhage, residual gradient, incomplete PDA closure, and side effects of vascular access during intervention, have been described [Huggon 1994; Celermajer 2002; Bacha 2001; Ralph-Edwards 1995].

There is a limited number of case series with hemodynamically significant coarctation that was treated with the 
transcatheter approach in the literature [Celermajer 2002; Uddin 2000; de Bono 2005; Roos-Hesselink 2003]. Multiple transcatheter interventions in the same session for treatment of PDA in combination with CoA have been reported by Turkay et al. [Turkay 2010]. Simultaneous treatment of native coarctation of the aorta combined with patent ductus arteriosus using a covered stent [Sadiq 2003], and stent implantation for aortoplasty and closure of patent ductus arteriosus using the Amplatzer duct occluder [Hakim 1999] have been described. Recoarctation after surgery or balloon angioplasty in infants, and a pulmonary embolic event by coil during PDA closure were reported [Uddin 2000; de Bono 2005; RoosHesselink 2003; Turkay 2010; Sadiq 2003; Hakim 1999].

Owing to some technical difficulties, it is not possible to treat low-weight babies who have PDA associated with an aortic coarctation in the same manner through an interventional approach. Therefore, surgery is inevitable in these patients. According to the authors, surgical treatment is accepted as a gold standard in patients younger than 6 months [Huggon 1994; Celermajer 2002; Bacha 2001; RalphEdwards 1995]. A case-control study comparing surgery and balloon dilatation demonstrated significantly lower re-intervention and complication rates after surgery compared to post balloon angioplasty [Uddin 2000; de Bono 2005; RoosHesselink 2003; Turkay 2010].

The management of a large PDA and hemodynamically significant aortic coarctation in the same session is controversial [Turkay 2010]. The seriously ill preterm infants presenting with medically intractable congestive heart failure is a specific entity. The authors traditionally preferred a transpleural approach for repairing CoA with the closure of PDA in the same session. This classical technique may increase the risk of bleeding, pneumothorax, hemothorax, or chylothorax as lifethreatening complications that may require revision surgery or longer intubation time after surgery. In order to prevent complications of transpleural technique during an isolated PDA closure procedure, a minimally invasive extrapleural approach or video-assisted thoracoscopy previously has been described in a limited number of reports [Früh 2011; Wyss 2005; Mazzera 2002; Vicente 2004; Iwase 2003; Leon-Wyss 2003; Pradegan 2020; Sersar 2005]. In our study, we present coarctation repair in combination with PDA closure in the same session using an extrapleural approach in critically ill children.

In this retrospective review, we aimed to analyze postoperative outcomes after an extrapleural approach and its efficacy in seriously ill infants who have hemodynamically significant PDA associated with coarctation over a 10 -year period.

\section{MATERIALS AND METHODS}

Forty-four babies ( $N=18$ neonates) with a large PDA associated with aortic coarctation were operated in two tertiary centers. Thirty patients were male. After approval by the hospitals' ethics committee, informed consent was obtained from each patient's family. In order to confirm the diameter and length of PDA, gradient from the coarcted segment and its location, as well as the type of pathology, transthoracic echocardiography (TTE) was performed prior to the surgery. The gestational age of neonates and infants was 29.9 \pm 4.5 weeks and $33.9 \pm 6.2$ weeks, respectively $(P=0.70)$. The median birth weight was $980 \pm 267 \mathrm{~g}$ in neonates and $1110 \pm 320 \mathrm{~g}$ in infants, respectively $(P=0.66)$. All patients received ibuprofen or indomethacin prior to the surgery. The mean weight at the time of surgery was $1650 \pm 370 \mathrm{~g}$ in neonates and $3450 \pm 660 \mathrm{~g}$ in the infant group, respectively $(P=0.034)$. The mean age at surgery was $28 \pm 4.3 \mathrm{~d}$ in neonates and $112.5 \pm 89.3 \mathrm{~d}$ in infants, respectively $(P=0.01)$. The size and length of PDA, median gradient from coarctation, and pulmonary artery pressures were measured using TTE for each patient. The length of the coarctation also was measured during surgery.

Patent foramen ovale, atrial septal defect, and ventricular septal defect were observed as intracardiac defects, which were hemodynamically insignificant. Twenty-eight infants had congestive heart failure with mild to moderate pulmonary hypertension. Patients' characteristics, including median gestational age, gender, and weight are summarized in Table 1. (Table 1)

We followed the patients in the early and late postoperative periods for the development of recoarctation and residual PDA flow, in terms of deaths and the need for reoperation. If we detected complications after surgery, such as the injury of parietal pleura and bleeding from anastomosis, the amount of blood transfusion, pulmonary complications such as atelectasis or pneumonia, neurologic events, and pleural effusion were noted in the early and late postoperative period.

Twenty-eight patients had CHF with mild or moderate pulmonary hypertension. All patients had systemic hypertension and received antihypertensive medication, including diuretics, angiotensin-converting enzyme inhibitors, and digitalis. We excluded the patients who had metabolic or bleeding disorders, immune deficiency, liver or kidney disease, or hemodynamically significant cardiac defect(s).

The operative data, including the duration of surgery, and aortic clamp time, were noted. The patients were evaluated during the follow-up period using physical examination, patients' weight, and findings of TTE. Patients' characteristics, including gestational age, age at the time of the operation, duration of mechanical ventilatory support, ICU, and hospital stay time, also were evaluated and compared.

Twenty patients already were intubated due to some comorbidities, hypoxia, or pulmonary disorders prior to the surgery. Operative data, including the duration of surgery, an aortic cross-clamp time, and postoperative gradient from the aorta, are summarized in Table 1. In addition, mortality, pulmonary complications related to cardiac or extracardiac defects, and post-surgery complications were evaluated. (Table 2)

We controlled echocardiography before discharging each patient home. Complications such as pneumothorax, chylothorax or hemothorax, or presence of residual coarctation were noted. We controlled pedal pulses in physical examination. TTE was performed to check whether there was any residual blood flow from the PDA in the early periods after the surgery. Mortality and recoarctation were end-points.

Surgical technique: After induction of general anesthesia, the patient was placed in the right lateral decubitus position for mini-posterolateral thoracotomy (Figure 1A). (Figure 
1) We preferred the 3rd or 4th intercostal space. The pleura was detached with blunt dissection away from the thoracic wall with careful attention to prevent entering into the pleural space (Figure 1B). The lung was retracted posteromedially to clearly expose the descending aorta and PDA. The left recurrent laryngeal and vagus nerves were clearly exposed and protected. After a clear identification of the CoA and PDA, we encircled both the CoA and PDA (Figure 2A and 2B). (Figure 2) We used double clips for the closure of the PDA. The descending aorta, as well as the proximal left subclavian arteries, were exposed and very carefully mobilized. Resection of coarctation with an extended end-to-end anastomosis was performed in 27 patients. We repaired CoA using a subclavian flap angioplasty technique in four infants. The subclavian flap technique was performed only in the presence of hypoplasia of the distal aorta. We used a biologic patch for repairing CoA in two patients.

Following the resection of the stenotic aortic segment with the remnant of PDA, we performed end-to-end anastomosis. After the completion of hemostasis, the lung was expanded to control the injury of the parietal pleura. The thoracic wall was closed without the use of chest wall drainage. (Figure 3) The patients were transferred to the ICU. Control chest $x$-ray film demonstrated that there was no pneumothorax, pleural fluids, or hemothorax in any patient. (Figure 4)

Statistical analysis: Analyses were performed using SPSS Version 19 (Illinois, Chicago, USA). Continuous variables were presented as mean value $\pm \mathrm{SD}$. We presented categorical variables with regard to frequencies and percentages. Pearson correlation analysis was used to explore possible correlations between mortality and demographic factors, such as gestational age at birth, weight at birth, weight at operation, and age in days at operation. Comparisons of categorical variables were made using the Fisher's exact or Chi-Square tests. To investigate risk factors for death and reoperation of aortic coarctation, we used Cox proportional regression analysis. We accepted statistical significance as $P<0.05$.

\section{RESULTS}

Preoperative echocardiographic findings, including the mean gradient of CoA, PDA length and diameter, are

Table 1. Demographic and the preoperative characteristics of the patients $(N=44)$

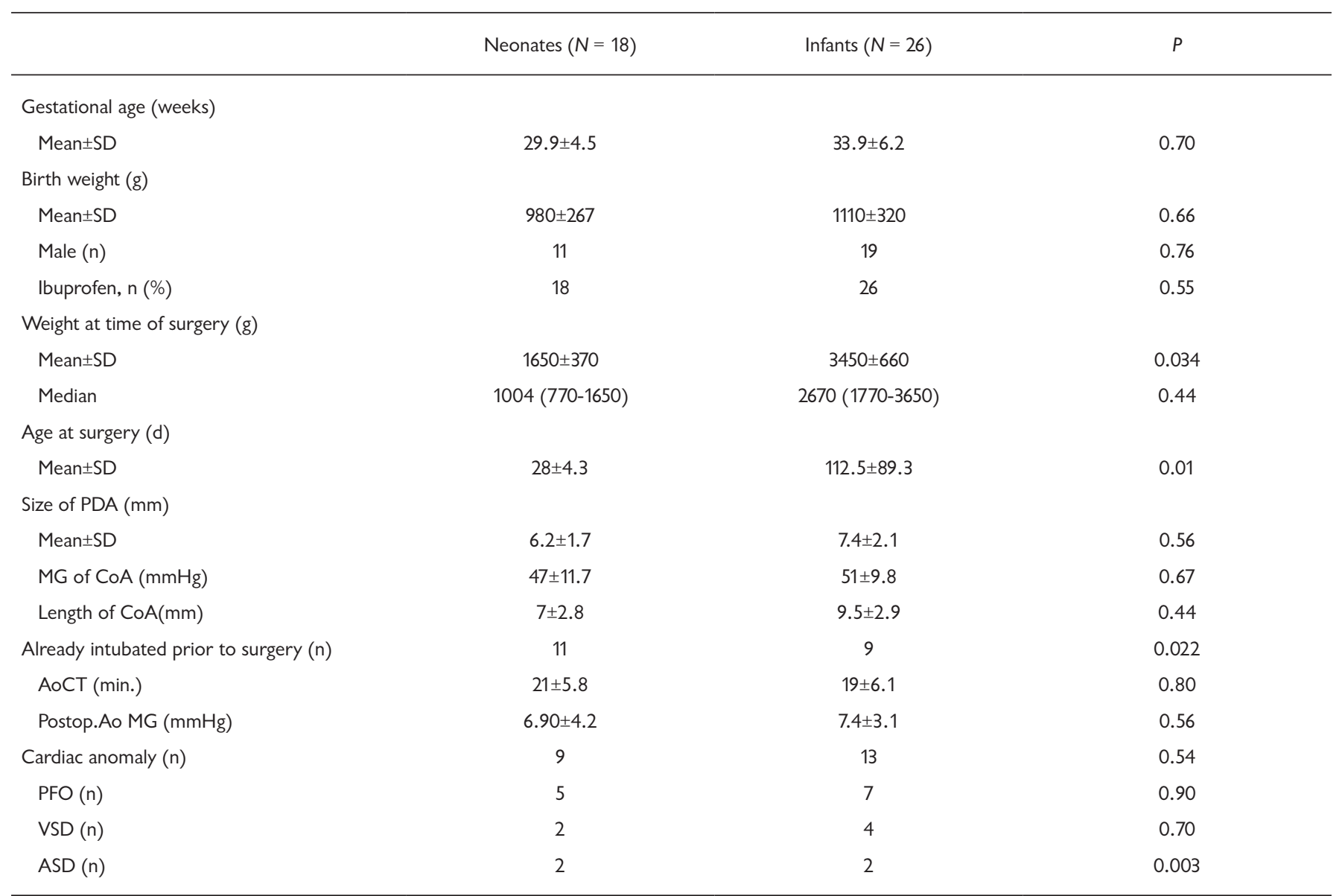

PDA, patent ductus arteriosus; SD, standard deviation; MG, mean gradient; AoCT, aortic cross-clamp time; Postop. MG, postoperative aortic mean gradient; PFO, patent foramen ovale; VSD, ventricular septal defect; ASD, atrial septal defect 
Table 2. Postoperative characteristics of the patients

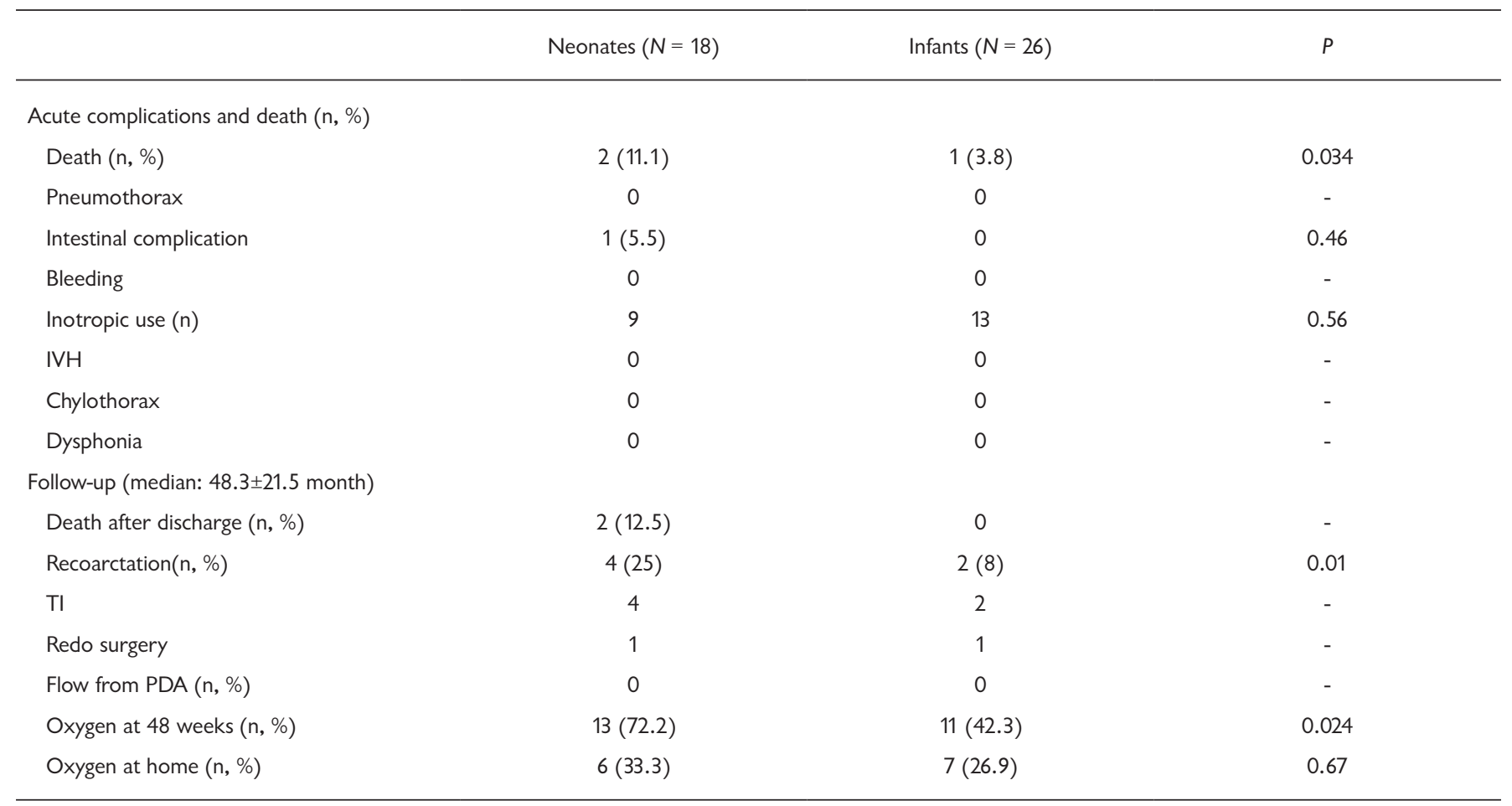

$\mathrm{IVH}$, intraventricular hemorrhage; $\mathrm{TI}$, transcatheter intervention

summarized in Table 1. Although ibuprofen was given to all patients before the operation, no closure or decrease in the flow was observed in PDA. The gestational age of neonates $(N=18)$ and infants was $29.9 \pm 4.5$ weeks and $33.9 \pm 6.2$ weeks, respectively. The birth weights of neonates and infants were $980 \pm 267 \mathrm{~g}$ and $1110 \pm 320 \mathrm{~g}$, respectively $(P=0.66)$. The patients' weight at the time of surgery was $1650 \pm 370 \mathrm{~g}$ in neonates and $3450 \pm 660 \mathrm{~g}$ in infants, respectively $(P=0.034)$. Preoperative echocardiography showed that the mean PDA diameter was $6.45 \pm 3.40 \mathrm{~mm}$ (range: $2.5-9 \mathrm{~mm}$ ). TEE showed there was no significant difference, when compared to the size of PDA in neonates and infants $(6.2 \pm 1.7 \mathrm{~mm}$ vs. $7.4 \pm 2.1 \mathrm{~mm})(P=$ $0.56)$. The median $( \pm \mathrm{SD})$ (IQR-interquartile range) preoperative gradient of coarctation was $47 \pm 11.7 \mathrm{mmHg}$ in neonates and $51 \pm 9.8 \mathrm{mmHg}$ in infants, respectively $(\mathrm{P}=0.67)$ (Table 1$)$.

At presentation, TTE demonstrated that there was congestive heart failure in 28 patients $(61.1 \%)$. Out of 28,19 patients were neonates. Because of the number of patients who had unstable hemodynamic situations and some comorbid disorders and hypoxia, we intubated 20 patients with ventricular dysfunction and pulmonary congestion preoperatively. Eleven neonates had bronchopulmonary dysplasia and moderate pulmonary hypertension. Acute respiratory distress syndrome (ARDS), sepsis, pneumonia, or pulmonary congestion were the main reasons for intubation.

Three patients died in the early postoperative period, two of whom were from the neonatal group (6.8\%). Congestive

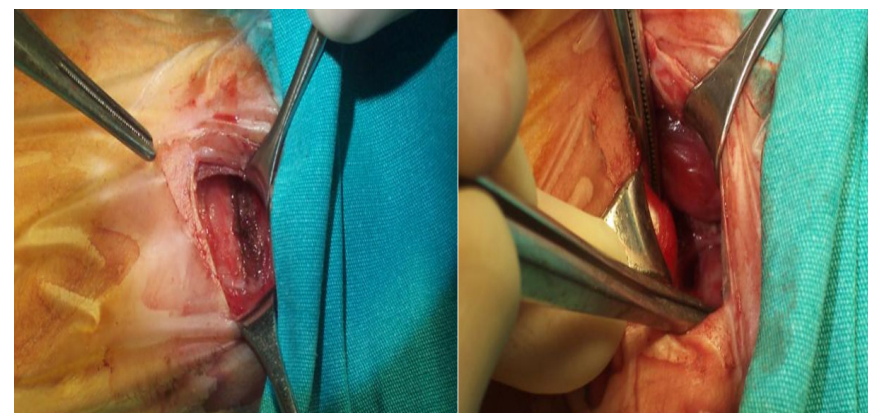

Figure 1. The posterolateral minithoracotomy incision. A) After the blunt dissection of visceral pleura, the right lung pushed posteriorly to expose patent ductus arteriosus and the descending aorta (B).

heart failure that was resistant to medical treatment, sepsis, and intestinal complications after surgery were the reasons for mortality factors.

In 12 patients, patent foramen ovale $(N=2)$, small muscular ventricular septal defect $(N=6)$, and atrial septal defects $(N=4)$ were additional cardiac pathologies that were hemodynamically insignificant. We intubated two neonates prior to the surgery because of intestinal or pulmonary reasons. We started antibiotics, digitalis, and diuretics. Neither necrotizing enterocolitis (NEC) nor intracranial hemorrhage was seen in the preoperative period. We successfully performed surgery 7-10 days after 
medical treatment in those two patients. Clinically significant anemia requiring transfusion was detected in four infants. A ventriculoperitoneal shunt was performed in two neonates with hydrocephalus two weeks after the cardiac surgery.

We genetically confirmed Down Syndrome (Trisomy-21) in three patients who were found to have duodenal atresia. Four weeks after the cardiac surgery, two of the three patients were operated on due to duodenal atresia. There was the presence of clinically significant hypothyroidism in five patients. Thyroid replacement therapy was applied to these patients by the endocrine department for 5-7 days before the operation. Since many of our patients had some comorbid diseases or additional anomalies, 2-3 doses of ibuprofen were administered. Despite the administration of ibuprofen, the continuation of PDA patency has been confirmed using TTE. Thus, surgery was decided after hemodynamic stability was achieved.

The postoperative results of the patients are summarized in Table 2. Echocardiographic examinations showed that the mean gradient after CoA repair in the neonates and infants was $6.5 \pm 3.8 \mathrm{mmHg}$ (range: $0-7.6 \mathrm{mmHg}$ ) and $4.8 \pm 1.1 \mathrm{mmHg}$ (range: $1.4-6.9 \mathrm{mmHg}$ ), respectively.

The median mechanical ventilatory support time was $44.3 \pm 33.9 \mathrm{~h}$ (range: $22.1-104 \mathrm{~h}$ ) in neonates. In the infant patients, ventilatory support was $25 \pm 14.9 \mathrm{~h}$ (range: 11.1-66.2 h). When comparing the intubation time of both groups, it was significantly longer in the neonates $(P=0.033)$. The mean hospital stay time was longer in the neonates when compared with the infants $(68.4 \pm 85.4 \mathrm{~d}$ vs. $38.4 \pm 55.9 \mathrm{~d})(P=0.001)$. Intubation time $\left(P^{l}=0.03\right)$ and supplementary oxygen requirement $\left(P^{2}=0.022\right)$ were significantly high in the neonates compared with the infants. Pre- and postoperative ARDS development, due to sepsis or pneumonia, was significantly high in the neonates. We think that the reasons for significant differences were lung immaturity, the easy vulnerability of neonates, and presence of bronchopulmonary dysplasia in neonates.

We did not detect residual flow from PDA or significant aortic gradient in any of our patients on postoperative control echocardiography. Postoperative pedal pulses were patent in all patients. Systemic hypertension regressed in all patients with the application of postoperative medication. In patients with pulmonary congestion due to cardiac reasons, symptoms improved significantly, and blood oxygen saturation increased after surgery. After achieving hemodynamic stability and adequate blood oxygen saturation, the neonates and infants were extubated. Neither phrenic nerve nor ductus thoracicus injury was seen. All patients underwent regular echocardiography before being discharged to their homes.

Follow-up period: The clinical results of patients' follow up are summarized in Table 2. Two neonates died during the follow-up period without any cardiac-related reason (4.8\%). One patient died because of sepsis in the 11th month. Another patient died due to a hemorrhage. TTE showed that PFOs, ASDs, and VSD closed spontaneously, except for two patients with ASD.

Recoarctation developed in six patients $(20 \%)$, four of whom were neonates. The mean gradient was $41 \pm 11.4 \mathrm{mmHg}$ (range: $24-56 \mathrm{mmHg}$ ). Systemic hypertension was detected in those six patients. TTE showed that there was no evidence of congestive heart failure in six patients. We performed

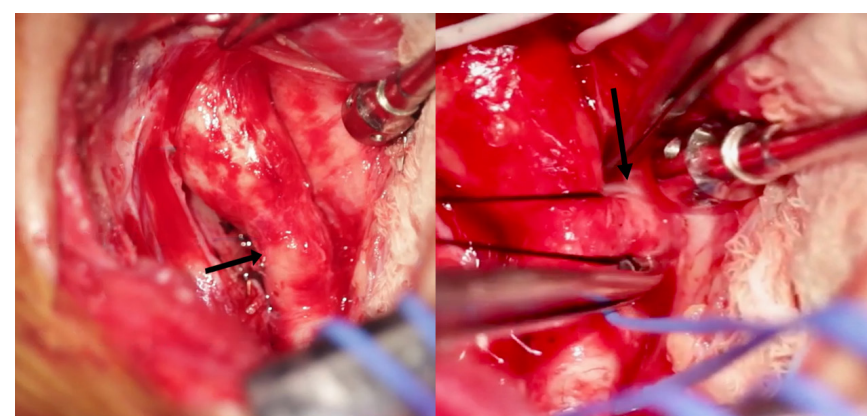

Figure 2. The coarctation of aorta (black arrowhead) and post-stenotic aortic dilatation $(\mathrm{A})$, and a large patent ductus arteriosus which is being encircled prior to clipping (Black arrowhead).

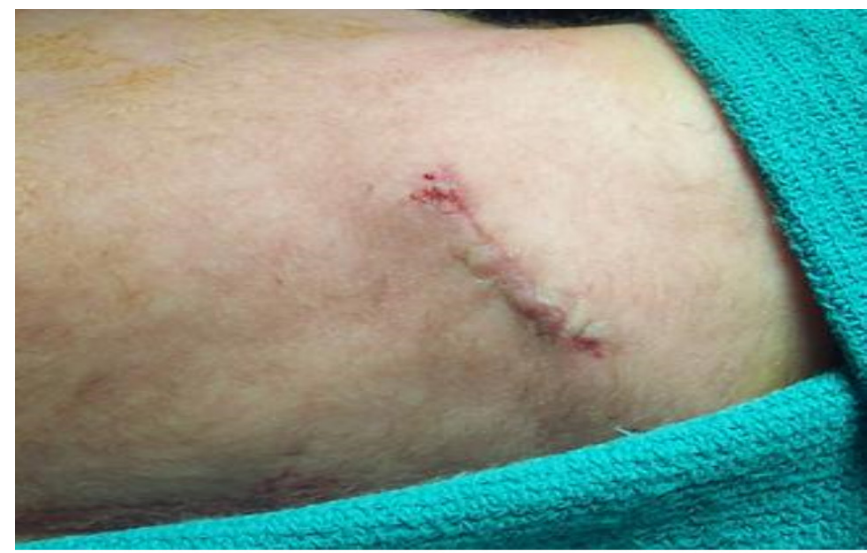

Figure 3. After closure of the thoracotomy incision. No tube thoracostomy is needed after the surgery.

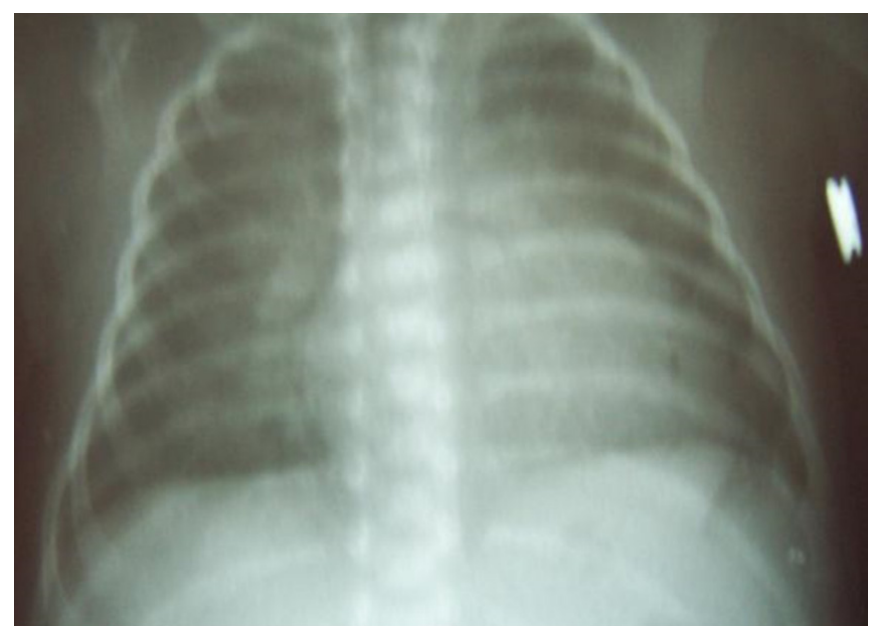

Figure 4. Chest X-ray film of a neonate in the intensive care unit. No pneumo- or hemothorax is seen. 
transcatheter balloon dilatation successfully in four patients. The median gradient decreased to $6.1 \pm 3.2 \mathrm{mmHg}$ (range:3.511.0). Because balloon dilatation failed in the remaining two patients, we performed reoperation through left posterolateral thoracotomy using a transpleural technique. No adhesion in the pleural space was seen related to the first surgery. An endto-end anastomosis was performed successfully in those two patients. The mean gradient after surgery was $4.1 \pm 1.9 \mathrm{mmHg}$ (range: $2-8 \mathrm{mmHg}$ ). Pedal pulses were patent in all patients after the interventions and surgeries. No mortality or morbidity was seen after interventions and surgical approaches. All six patients were extubated in the operating room. Two patients required inotropic administration for two days in the ICU, and we discharged all patients without complications.

During the first operation in our six patients who developed recoarctation, we found a high preoperative gradient (35 mmHg and above) and CoA segment length longer than $10 \mathrm{~mm}$. Transthoracic echocardiography showed normal left ventricular dimensions and systolic function in $80 \%$ of the patients. The mean weight at the last control echocardiography reached $14.6 \pm 5.3 \mathrm{~kg}$ (range: $2344-16400 \mathrm{~g}$ ). No complication (e.g., chylothorax, hemothorax, or pneumothorax) was detected during the follow-up period.

\section{DISCUSSION}

Patent ductus arteriosus associated with an aortic coarctation is a common cardiovascular pathology in premature infants. Conservative treatment, interventional, or surgical approaches are being used to treat this pathology. Fluid restriction, digitalis, and diuretics administration are being used in conservative treatment. In addition, ventilation strategies, advances in medication, including exogenous surfactant administration, increase spontaneous PDA closure. However, the treatment of hemodynamically significant aortic coarctation associated with PDA is controversial, especially in infants with congestive heart failure [Huggon 1994; Celermajer 2002; Bacha 2001; Ralph-Edwards 1995]. In premature newborns with a CoA, resection of coarctation segment with an end-toend anastomosis has been accepted as the gold standard therapeutic option in a number of centers until the 1980s [Huggon 1994; Celermajer 2002; Bacha 2001; Ralph-Edwards 1995; Uddin 2000; de Bono 2005; Roos-Hesselink 2003]. Since the early period of the 1980s, transcatheter treatment has been described for the treatment of native coarctation [Redington 1990; Huggon 1994; Celermajer 2002]. For the closure of PDA, a transcatheter intervention using a coil or Amplatzer device has been introduced at the same time [Jaillard 2006; Turkay 2010; Sadiq 2003; Hakim 1999; Früh 2011]. Balloon angioplasty for treating coarctation with PDA closure using a coil or Amplatzer device in the same session as an interventional approach has been proposed as an alternative to surgery [Roos-Hesselink 2003; Turkay 2010; Sadiq 2003; Hakim 1999; Früh 2011]. Unfortunately, the recoarctation rate is high after interventional approach, especially in low-birthweight infants and neonates [Turkay 2010; Sadiq 2003; Hakim 1999; Früh 2011; Wyss 2005; Mazzera 2002; Vicente 2004].
Therefore, re-intervention using transcatheter or surgery has been proposed [Redington 1990; Huggon 1994; Celermajer 2002; Bacha 2001; Ralph-Edwards 1995; Uddin 2000; de Bono 2005; Roos-Hesselink 2003; Turkay 2010].

In surgery, the transpleural technique for closure of PDA and coarctation repair, are being used in a number of centers. Since it has some complications, such as pleural effusion or phrenic nerve damage, an extrapleural or video-assisted minimally invasive surgery have been described for the closure of PDA in critically ill patients [Früh 2011; Wyss 2005; Mazzera 2002; Vicente 2004; Iwase 2003; Leon-Wyss 2003; Pradegan 2020; Sersar 2005; Demirturk 2011; Chen 2011; Villa 2004]. No report has been published concerning PDA closure in combination with coarctation repair in the same session using an extrapleural technique in neonates or infants with congestive heart failure. Thus, to our knowledge, we presented our experiences of extrapleural surgical technique for the closure of PDA and coarctation repair in children with hemodynamically significant PDA associated with native aortic coarctation and their clinical outcomes for the first time in literature. We administered antihypertensive medication, including digitalis and diuretics, in hemodynamically unstable patients prior to their surgery. In patients who were resistant to medical treatment or conservative management, we preferred surgery in neonates with congestive heart failure. We preferred resection of the coarcted segment and extended end-to-end anastomosis or subclavian flap aortoplasty. Postoperative peak-to-peak gradients were within normal limits, and pedal pulses were patent in our patients. We observed that the congestive heart failure improved, and the ventilation support time decreased dramatically after surgery. We initially suggest a conservative approach in hemodynamically stable patients with a PDA diameter lower than $2 * 3 \mathrm{~mm}$, and a gradient from the coarctation segment that is between $20-30 \mathrm{mmHg}$. We restricted fluid administration, diuretics, and antihypertensive drugs for 3-5 days. Therefore, surgery may be delayed in these types of patients.

The recurrence rate of CoA after surgery or transcatheter balloon angioplasty was higher in patients whose age was lower than 6 months [Redington 1990; Huggon 1994; Celermajer 2002; Bacha 2001; Ralph-Edwards 1995; Uddin 2000; de Bono 2005; Roos-Hesselink 2003; Turkay 2010]. In case of the recurrence of coarctation after surgery or balloon angioplasty, then transcatheter re-intervention may be performed as a therapeutic option. Unfortunately, an aortic aneurysm or periaortic hematoma may be seen after the transcatheter intervention. In most premature babies whose weight is $1,000 \mathrm{~g}$ or less, CoA associated with PDA may go on to become hemodynamically significant, and thus, it will require immediate medication and surgery. Surgical ligation or interventional closure of PDA using a coil or Amplatzer may be performed immediately if patients have a hemodynamically significant case that results in cardiac dysfunction and respiratory failure. Ligation of PDA may be performed via transpleural or extrapleural technique using a clip or tying. Some adverse effects, such as phrenic nerve injury, bronchopulmonary dysplasia, NEC and IVH, may be seen after surgery of PDA in combination with CoA repair.

Complications encountered during or after balloon angioplasty for both native and recurrent coarctation include 
femoral artery injury, dissection of the entry side, and aneurysm formation. Stenting during coarctation angioplasty has been suggested in older children ( $\geq 6$ years) since the use of stent implantation has some limitations [Sadiq 2003; Hakim 1999; Früh 2011]. Complications encountered during or after stent implantation are similar to those encountered after balloon angioplasty, with the added potential risk of stent malposition [Hakim 1999; Früh 2011].

The authors suggested that transcatheter interventions, including stent implantation following balloon angioplasty in older children, might be decided [Sadiq 2003]. In children whose ages are more than 6 years, some authors preferred stent implantation with the use of a 5-14 mm length balloon with a maximum pressure of $3.5 \mathrm{~atm}$ to achieve the dilatation of the aortic coarctation [Hakim 1999; Früh 2011]. The authors showed that there was a higher decrease in the gradient of patients treated with surgery $(70.2 \%)$ compared with balloon dilatation (34.4\%). Früh et al. showed that there was a lower residual gradient after stent implantation compared with balloon dilatation in patients who are older than 6 years (73.7\% vs. 10.3\%) [Früh 2011]. Transcatheter intervention, surgery, and hybrid procedures as treatment options have been suggested depending on the patient's age, anatomic properties of the pathology, and the size of PDA associated with aortic coarctation in previous reports [Jaillard 2006; Redington 1990; Huggon 1994; Celermajer 2002; Bacha 2001; Ralph-Edwards 1995; Uddin 2000; de Bono 2005; Roos-Hesselink 2003; Turkay 2010].

Infants with a peak-to-peak coarctation gradient $\geq 20$ $\mathrm{mmHg}$ is accepted as a critical point, which is the risk for sudden death when PDA closes. In order to provide patency of PDA prior to surgery or intervention, continuous intravenous infusion of prostaglandin E1 is essential.

With surgical experiences and technological advancement, successful trans- and extrapleural or minimally invasive (endoscopic) surgical approaches may prevent late complications such as scoliosis, winged scapula, chest wall deformities, breast malformation, and rib fusion after the transpleural technique, which also may cause secondary respiratory compromise. The advantage of an extrapleural technique has been described in a limited number of patients [Wyss 2005; Mazzera 2002; Vicente 2004; Iwase 2003; Leon-Wyss 2003; Pradegan 2020; Sersar 2005; Demirturk 2011].

To our knowledge, closure of PDA in combination with the repair of CoA at the same session using the extrapleural approach in seriously ill babies was not previously reported. Our aim of retrospective review has focused on clinical results of surgical approach after surgical coarctation repair combined with PDA closure in neonates and infants. We presented clinical results of our patients in the early stages and at the end of the follow-up period. We compared mortality and morbidity rate, intubation and hospitalization period, and ICU stay-time of our groups (neonates and infants older than 6 months). According to our results, we suggest an extrapleural technique for the closure of PDA using double clipping in combination with end-to-end anastomosis technique in critically ill children with or without congestive heart failure and its complications. No side effects or complications were detected related to our technique as a less invasive method.

The clinical results of medication or surgery of small infants and neonates with an isolated PDA have been reported in a number of studies [Villa 2004; Alexander 2009; Uddin 2000; Villa 2005; Alvarez 2015]. However, the results of different treatment methods of PDA associated with coarctation have not been well studied. Thus, we need prospective randomized clinical trials and comparisons between the treatment methods, including the conservative option, transcatheter intervention, and surgery for each age group. Many centers preferred an interventional approach in patients with an isolated PDA or coarctation of the aorta. Because the recoarctation rate is high after the percutaneous approach in small children, surgery may be decided as a first option. Thus, minimally invasive surgery, such as video-assisted thoracoscopic surgery (VATS) or extrapleural technique was performed as alternative options. However, body weight is one of the main restrictions for VATS, and its price is high for poor and developing countries.

The extrapleural option was chosen due to earlier reports of successful PDA used for term and preterm infants in our experiences. Two new minimally invasive techniques are described by Mazzera et al. [Mazzera 2002] and Vicente et al. [Vicente 2004]. Wyss et al. described the modified extrapleural ligation of patent ductus arteriosus as a convenient surgery [Wyss 2005]. Mazzera et al. and Vicente et al. described the transverse cervicectomy approach and the dorsal minithoracotomy method for clipping PDA alone.

Our technique may lead to minimal stress on organ systems, such as the intestine, liver, or kidney. No complications such as NEC, IVH, parietal pleura injury, and neural damage were detected during and after the surgery. In our cohort, the operation needs only a central line and the radial and femoral arterial monitorization of systemic pressure. Because this technique does not require thoracic tube thoracostomy after surgery, the quality of life of these babies was found to be more comfortable. Since performing tube thoracostomy might increase the risk for atelectasis of the lung, we avoided tube thoracostomy. Our technique includes less dissection with muscle-sparing and obviates encircling of the PDA, and descending aorta, both of which result in less risk of hemorrhage or other surgical complications. We provide better hemodynamics, and also an excellent surgical exposure of the left recurrent nerve and the thoracic duct. Thanks to the extrapleural technique, we may avoid injury to the left recurrent nerve, vagus or ductus thoracicus.

In a previous report of preterm neonates, the authors reported bleeding, pneumothorax, hemothorax, vocal cord paralysis, chylothorax, and injury to the phrenic nerve [Mandhan 2009]. According to our retrospective review, complications after PDA and coarctation repair surgery may be decrease using the extrapleural approach. However, we need a comparative study to define whether the extrapleural approach has advantages over another techniques. No nerve injury, chylothorax, pneumothorax, or bleeding in our babies was detected compared to our transpleural approach for PDA in premature infants. Some rare complications may be seen after surgery in some patients, such as a residual gradient after coarctation repair or inadvertent closure of the PDA. 


\section{CONCLUSION}

Conservative treatment may be the first choice in hemodynamically stable children who have PDA associated with aortic coarctation. Extrapleural minithoracotomy technique may be used with a less invasive surgical option by an experienced surgeon for the closure of PDA in combination with coarctation repair in the same session. Recoarctation may be seen during the follow-up period (in 20\% of patients of our series). An extrapleural technique may provide some advantage with a low complication rate for critically ill neonates and small infants. We conclude that this technique is a safe, cost-effective, and an effective method in selected neonates and small infants with a comorbid disease.

Study limitations: We operated on a limited number of patients who underwent PDA closure and coarctation repair in the same session and presented the clinical outcomes of the patients in the last decade in our clinic. Unfortunately, we presented a small number of patients, and a control group was unavailable in our study. We also could not present a comparison of the surgical outcomes and interventional approaches.

\section{REFERENCES}

Alexander F, Chiu L, Kroh M, Hammel J, Moore J. 2009. Analysis of outcome in 298 extremely low-birth-weight infants with patent ductus arteriosus. J Pediatr Surg. 44:112-117.

Alvarez D, Serantes L, Lourida RB, Rodrigues CB, Torronc FP, Hernandez VB. 2015. Surgical closure of patent ductus arteriosus in premature neonates: Does the surgical technique affect the outcome? Ann Ped. $86 ; 277-83$.

Bacha EA, Almodovar M, Wessel DL, Zurakowski D, Mayer JE Jr, Jonas RA, et al. 2001. Surgery for coarctation of the aorta in infants weighing less than $2 \mathrm{~kg}$. Ann Thorac Surg. 71;1260-4.

Celermajer DS, Greaves K. 2002. Survivors of coarctation repair: fixed but not cured. Heart. 88:113-14.

Chen H, Weng G, Chen Z, Wang H, Xie Q, Bao J, Xiao R. 2011. Comparison of posterolateral thoracotomy and video-assisted thoracoscopic clipping for the treatment of patent ductus arteriosus in neonates and infants. Pediatr Cardiol. 32:386-390.

de Bono J, Freeman LJ. 2005. Aortic coarctation repair-lost and found: the role of local long term specialised care. Int J Cardiol. 104:176-83.

Demirturk OS, Guvener M, Coskun I, Tunel HA. 2011. Results from extrapleural clipping of a patent ductus arteriosus in seriously ill preterm infants Pediatr Cardiol. 32(8):1164.

Früh S, Knirsch W, Dodge-Khatami A, Dave H, Prêtre R, Kretschmar O. 2011. Comparison of surgical and interventional therapy of native and recurrent aortic coarctation regarding different age groups during childhood. Eur J Cardiothorac Surg. 39:898-904.

Hakim F, Hawelleh AA, Goussous Y, Hijazi ZM. 1999. Simultaneous stent implantation for coarctation of the aorta and closure of patent ductus arteriosus using the Amplatzer duct occluder. Catheter Cardiovasc Interv. 47:36-38.

Huggon IC, Qureshi SA, Baker EJ, Tynan M. 1994. Effect of introducing balloon dilation of native aortic coarctation on overall outcome in infants and children. Am J Cardiol. 73;799-807.

Iwase J, Tajima K, Io A, Katoh W, Tanaka K, Toki S, Iwasa M, Sobajima H, Takasu H, Yamada Y. 2003. Less invasive surgical closure of patent ductus arteriosus in extremely low-birth-weight infants. Jpn J Thorac Cardiovasc Surg. 51:651-655.

Jaillard S, Larrue B, Rakza T, Magnenant E, Waremburg H, Storme L. 2006. Consequences of delayed surgical closure of patent ductus arteriosus in very premature infants. Ann Thorac Surg. 81:231-235.

Leon-Wyss J, Vida V, Veras O, Vides I, Gaitan G, O'Connell M, Castan`eda AR. 2003. Modified extrapleural ligation of patent ductus arteriosus: a convenient surgical approach in a developing country. Ann Thorac Surg. 79:632-635.

Mandhan P, Brown S, Kukkady A, Samarakkody U. 2009. Surgical closure of patent ductus arteriosus in preterm low birth weight infants Congenit Heart Dis. 4(1):34-7.

Mazzera M, Brancaccio G, Feltri C, Michielon G, Di Donato R. 2002. Minimally invasive surgical closure of patent ductus arteriosus in premature infants: a novel approach. J Card Surg. 17:292-294.

Pradegan N, Muñoz YM, Vida VL, Leon-Wyss JR. 2020. Extrapleural Closure of Patent Ductus Arteriosus: How We Do I? Braz J Cardiovasc Surg. 35;831-833.

Ralph-Edwards AC, Williams WG, Coles JC, Rebeyka IM, Trusler GA, Freedom RM. 1995. Reoperation for recurrent aortic coarctation. Ann Thorac Surg. 60:1303-7.

Redington AN, Booth P, Shore DF, Rigby ML. 1990. Primary balloon dilatation of coarctation of the aorta in neonates. Br Heart J. 64:277-81.

Roos-Hesselink JW, Schölzel BE, Heijdra RJ, Spitaels SE, Meijboom FJ, Boersma E, et al. 2003. Aortic valve and aortic arch pathology after coarctation repair. Heart. 89:1074-7.

Sadiq M, Malick NH, Qureshi SA. 2003. Simultaneous treatment of native coarctation of the aorta combined with patent ductus arteriosus using a covered stent. Catheter Cardiovasc Inter. 59:387-390.

Sersar SI, Mooty HA, Hafez MM, Ismail MF, Refaat AA, Ibrahim MF. 2005. PDA ligation: trans or extrapleural approach. Ann Thorac Surg. $80 ; 1976$.

Turkay S, Abdullah E, Celal A, Cenap Z, Nurdan E, Fadli D. 2010. Multiple transcatheter interventions in the same session in congenital cardiopathies. J Cardiovasc Dis Res. 1;181-190.

Uddin MJ, Haque AE, Salama AL, Uthman BC, Abushaban LA, Shuhaiber HJ. 2000. Surgical management of coarctation of the aorta in infants younger than five months: a study of fifty-one patients. Ann Thorac Cardiovasc Surg. 6:252-7.

Vicente WA, Rodrigues AJ, Ribeiro PJ, E’ vora PR, Menardi AC, Ferreira CA, Alves L, Bassetto S. 2004. Dorsal minithoracotomy for ductus arteriosus clip closure in premature neonates. Ann Thorac Surg. 77:1105-1106.

Villa E, Frédéric Eynden V, Le Bret E, Folliguet T, Laborde F. 2004. Pediatric video-assisted thoracoscopic clipping of patent ductus arteriosus: experience in more than 700 cases Eur J Cardiothorac Surg. 25:387-93.

Villa E, Mazzera E, Galetta D, Di Donato RM. 2005. Patent ductus arteriosus in neonates and new approachs. Ann Thorac Surg. 79:1827-8.

Wyss LJ, Vida VL, Veras O, et al. 2005. Modified extrapleural ligation of patent ductus arteriosus: a convenient surgical approach in a developing country. Ann Thorac Surg. 79;632-35. 